\title{
STUDY OF OPTIC NERVE SHEATH DIAMETER IN NORMAL NEPALESE ADULTS USING ULTRASOUND
}

\author{
$K C B^{1^{*}}$, Thapa $A^{2}$
}

\section{Affiliation}

1. Lecturer, Department of Neurological Surgery, Kathmandu Medical College

2. Associate Professor, Department of Neurological Surgery, Kathmandu Medical College

\section{ARTICLE INFO}

\section{Article History}

Received : 26February, 2018

Accepted : 29 March, 2018

Published : 30 April, 2018

(C) Authors retain copyright and grant the journal right of first publication with the work simultaneously licensed under Creative Commons Attribution License CC - BY 4.0 that allows others to share the work with an acknowledgment of the work's authorship and initial publication in this journal.

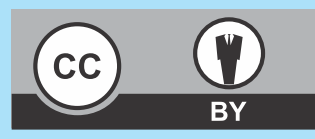

\section{ORA 56}

DOI: $\underline{\text { http://dx.doi.org/10.3126/bjhs.v3i1.19758 }}$

\section{* Corresponding Author}

\section{Dr Bidur KC}

Lecturer

Department of Neurological Surgery

Kathmandu Medical College, Sinamangal, Kathmandu, Nepal Email:kcbidur@gmail.com

https://orcid.org/0000-0003-3691-8764

\section{Citation}

KC B, Thapa A. Study of Optic Nerve Sheath Diameter In Normal Nepalese Adults Using Ultrasound. BJHS 2018;3(1)5:357 - 360.

\section{ABSTRACT}

\section{Introduction}

Though invasive intracranial devices are gold standard to calculate intracranial pressure (ICP); these are not without any complications. Non-invasive measurement of ICP by Ultrasonography could be a safe and portable technique.

\section{Objectives}

The objective of the study was to measure and compare values of optic nerve sheath diameter of both eyes in healthy Nepalese adults.

\section{Methodology}

A prospective cross-sectional study of healthy adult Nepalese volunteers was performed using a $7.5 \mathrm{MHz}$ linear Ultrasound probe on the closed eyelids; optic nerve sheath diameter (ONSD) was measured $3 \mathrm{~mm}$ behind the globe in each eye.

\section{Results}

Optic nerve sheath diameter (ONSD) of both eyes was measured in 100 healthy volunteers of age ranged from 15 to 75 years with a mean of $30.21 \pm 14.05$ years. There were $18(18 \%)$ male and $82(82 \%)$ female. ONSD for right eye ranged from 3.20 to $4.90 \mathrm{~mm}$ with mean of $4.10 \pm 0.50 \mathrm{~mm}$ and left eye from 3.20 to $4.80 \mathrm{~mm}$ with mean of $4.22 \pm 0.49$ $\mathrm{mm}$. $P$ value for right and left eye ONSD $(P=0.06)$ and male and female $(P=0.12$ and 0.85 for right and left ONSD respectively) were within normal limits. ONSD has no correlation with age $(P=0.27$ and 0.27 for right and left ONSD respectively).

\section{Conclusion}

Mean of optic nerve sheath diameter (ONSD) is $4.10 \mathrm{~mm}$ and $4.22 \mathrm{~mm}$ for right and left eye respectively. There is no statistical significant difference in mean of ONSD between right and left eye.

\section{KEY WORDS}

Healthy volunteers, nepalese adult, optic nerve sheath diameter, transorbital sonography 


\section{INTRODUCTION}

The optic nerve, is a second cranial nerve (CNII), derived from embryonic retinal ganglion cell. Also known as the nerve of vision because it carries the electrical impulses from retina to brain. It is myelinated nerve wrapped with three meningeal layers of which subarachnoid space is continuous with that of the brain. ${ }^{1-3}$ Hence, change in intracranial pressure (ICP) causes reflective change in intraorbital subarachnoid space pressure at the same time. ${ }^{1,4,5}$

Gold standard for ICP measurement are Invasive intracranial devices. ${ }^{6,7}$ However, these devices may invite complications like infection, hemorrhage and dislodgement. Besides, it cannot be performed in cases of bleeding disorders. ${ }^{8-10}$ There lies the significance of measuring ICP non-invasively. ${ }^{11}$

Detection of papilloedema to infer Increase in ICP non invasively mandates an experienced examiner and usually occurs late. ${ }^{12,13}$ Other noninvasive devices like Computed tomography (CT) and magnetic resonance imaging (MRI) of the head which may not be accessible everywhere, are expensive and may not be portable. ${ }^{14,15}$ Bulbar ultrasonography also detects increase in ICP non-invasively before development of papilloedema which is corroborated by Invitro studies. ${ }^{16}$ Optic nerve sheath diameter (ONSD) has been utilized for different conditions to find increase in ICP as a clinical and research tool with high sensitivity and ONSD differs almost simultaneously with ICP. ${ }^{17-19}$ It is cheap and easy to train operators. Unlike other ultrasound methods, has low intra and inter-operator variability. ${ }^{20,21}$

There is no consensus of threshold value ONSD pointing increased ICP. It may vary from person to person but doesn't vary among children of different sex. ${ }^{19,22}$ Widely acceptable value for adult is $5 \mathrm{~mm}$, although maximum of $5.9 \mathrm{~mm}$ have been quoted. ${ }^{19}$ Normal values of ONSD can be used to infer increase in ICP in medical practice. ${ }^{17,23}$ ONSD can vary with ethnic origin. Asian countries have found different normal ranges in adults (3.7-4.7 $\mathrm{mm}$ in Hong Kong, $2.9-5.3 \mathrm{~mm}$ in Korea and 4.25-4.75 mm in Bangladesh). ${ }^{5,23,24}$

Besides, there is a paucity of local data of ONSD in Nepalese adults, so this study aims to evaluate the baseline value of ONSD among healthy Nepalese adults.

\section{METHODOLOGY}

This prospective cross-sectional study was conducted in department of Neurological Surgery at Kathmandu Medical College Hospital (KMCH) in Sinamangal, Kathmandu, Nepal from $5^{\text {th }}$ January 2018 to $15^{\text {th }}$ February 2018. Apparently healthy hospital staffs, medical students and relatives of the patients above 16 years were enrolled after obtaining informed consent. Those with ocular diseases, neurological disorder, features of raised ICP, non Nepalese and aged 16 years or below were excluded from the study. The study was approved by ethical review committee of $\mathrm{KMCH}$.

ONSD was measured using $7.5 \mathrm{MHz}$ linear array transducer of the Mindray Diagnostic Ultrasound System (Model: Z6; Shenzhen Mindray Biomedical Electronics Co., Ltd., Shenzhen- 518057, P.R. China) by a single sonographer. As low as reasonably achievable (ALARA) ultrasonography technique was used for the safety of the volunteers. Volunteers were placed in supine position with closed eyelid. After applying gel at the temporal side of eyelid, transducer was kept horizontally. Transducer was adjusted till appearance of hypoechoic optic nerve behind the globe. ONSD of both eyes were measured at $3 \mathrm{~mm}$ behind the globe taking transverse diameter of hypoechoic shadow right angle to the optic nerve by using electronic caliper. Coupling gel was removed with sterile paper from the transducer and clean with normal saline after each use. Data were collected and entered into the excel sheet.

Statistical analysis was performed using IBM SPSS Statistics version 22 (IBM Corporation, New York, USA). Data were analyzed with descriptive and inferential statistics. Paired T test was used to compare the mean ONSD of right and left eye. Mann-Whitney $U$ test was used to determine correlation between the gender and ONSD and Kruskal-Wallis test to evaluate correlation between age and ONSD. P values of $<0.05$ were considered significant.

\section{RESULTS}

Total of 100 subjects were included. Among them, 18 (18\%) were male and 82 (82\%) were female. Age ranged from 17 to 75 years, with a mean of $30.21 \pm 14.05$ years.

ONSD value for right eye ranged from $3.20 \mathrm{~mm}$ to $4.90 \mathrm{~mm}$ with mean of $4.10 \pm 0.50 \mathrm{~mm}$ and median of $4.1 \mathrm{~mm}$. ONSD value for left eye ranged from $3.20 \mathrm{~mm}$ to $4.80 \mathrm{~mm}$ with mean of $4.22 \pm 0.49 \mathrm{~mm}$ and median of $4.4 \mathrm{~mm}$. There was no statistically significant difference of mean ONSD between right and left eye $(P=0.06)$. This study showed no statistically significant association of ONSD between male and female $(P=0.12$ and 0.85 for right and left ONSD respectively). No statistically significant correlation was found between ONSD and age $(P=0.27$ and 0.27 for right and left ONSD respectively).

\section{DISCUSSION}

Most of the neurosurgical patients usually died of raised ICP; head injury is not an exception. ${ }^{25,26}$ An increase in ICP impedesthe cerebral blood flow (CBF) leading to ischaemia. ${ }^{27,28}$ Secondary brain-injury due to raised ICP is a poor outcome predictor after traumatic brain injury. Treatment algorithms focuses on prevention of these insult. $^{28}$

Neurological intensive care is vital for immediate treatment after picking up subclinical causes of secondary brain injury. ${ }^{29}$ ICP monitoring is beneficial in many studies to prevent surgery in the settings of normal initial CT scan. ${ }^{30}$ Mortality has been decreased with effective treatment of raised ICP. ${ }^{26}$ For effective utilization of ONSD in the situation of raised ICP, normal reference value is required. 
Several studies have observed variation of ONSD in normal subjects by using ultrasonography as shown in Table 1. Maude et al found Median ONSD was $4.41 \mathrm{~mm}$ with $95 \%$ of subjects in the range $4.25-4.75 \mathrm{~mm}$ in Bangladesh. Among 100 Pakistani healthy subjects, Ali et al reported ONSD of 4.3-5.7 mm. ${ }^{23,31}$ Bauerle et al in German showed normal range of 4.3-7.6 $\mathrm{mm}$ among 40 subjects with mean of 5.4 $\mathrm{mm} .^{20}$ The median ONSD of $4.1 \mathrm{~mm}$ with range of 3.1-4.6 $\mathrm{mm}$ was observed by Shrestha in 80 healthy Nepalese subjects. ${ }^{32}$ Chan et al ${ }^{5}$ calculated the normal range from 3.7 $\mathrm{mm}$ to $4.7 \mathrm{~mm}$ with a mean of $4.05 \pm 0.19 \mathrm{~mm}$ among 100 normal Hong Kong Chinese adult. Our study revealed the range of $3.20 \mathrm{~mm}$ to $4.90 \mathrm{~mm}$ with mean of $4.10 \pm 0.50 \mathrm{~mm}$ for the right eye and $3.20 \mathrm{~mm}$ to $4.80 \mathrm{~mm}$ with mean of

\section{CONCLUSION}

Mean of optic nerve sheath diameter (ONSD) in healthy Nepalese adults for the right and left eye is $4.10 \pm 0.50$ and $4.22 \pm 0.49 \mathrm{~mm}$ respectively. There is no significant statistical association between ONSD of right and left eyes, ONSD and age and gender and side.

\section{RECOMMENDATION}

Should be used as a bedside screening tool in all patients suspicious of raised ICP. These calculated values of ONSD of healthy Nepalese adults would be used as a baseline for future reference in patients with raised ICP.

Table 1. ONSD variation in different countries

\begin{tabular}{|c|c|c|c|c|c|}
\hline Study & Country of Study & \multicolumn{2}{|c|}{ ONSD range in $\mathrm{mm}$} & \multicolumn{2}{|c|}{ Mean $^{\mathrm{a}} /$ Median $^{\mathrm{b}}$ ONSD in $\mathrm{mm}$} \\
\hline Maude et al $^{23}$ & Bangladesh & \multicolumn{2}{|c|}{$4.2-4.7$} & \multicolumn{2}{|c|}{$4.4^{\mathrm{b}}$} \\
\hline Ali et $a l^{31}$ & Pakistan & \multicolumn{2}{|c|}{$4.3-5.7$} & \multicolumn{2}{|c|}{$4.8^{\mathrm{b}}$} \\
\hline Bauerle et $\mathrm{al}^{20}$ & German & \multicolumn{2}{|c|}{$4.3-7.6$} & \multicolumn{2}{|c|}{$5.4^{a}$} \\
\hline Shrestha ${ }^{32}$ & Nepal & \multicolumn{2}{|c|}{$3.1-4.6$} & \multicolumn{2}{|c|}{$4.1^{b}$} \\
\hline Chan et $\mathrm{al}^{5}$ & Hong Kong, China & \multicolumn{2}{|c|}{$3.7-4.7$} & \multicolumn{2}{|c|}{$4.05^{\mathrm{a}}$} \\
\hline \multirow[t]{2}{*}{ This study } & \multirow[t]{2}{*}{ Nepal } & Right & Left & Right & Left \\
\hline & & $3.2-4.9$ & $3.2-4.8$ & $4.1^{\mathrm{a}}$ & $4.2^{\mathrm{a}}$ \\
\hline
\end{tabular}

$4.22 \pm 0.49 \mathrm{~mm}$ for the left eye was similar to the values observed by Maude et al in Bangladesh, Shrestha in Nepal and Chan et al in Hongkong. ${ }^{5,23,32}$ However, our values were lower than what has been reported by Ali et al in Pakistan and Bauerle et al in Germany. ${ }^{20,31}$

In concordance with previous studies, our study also concluded no statistically significant association between ONSD and age, gender and side.

\section{REFERENCES}

1. Ryan S, Nicholas MM, Eustace S. Anatomy for Diagnostic Imaging.2nd ed. Philadelphia (US): Elsevier Limited; 2004.

2. Ellis $\mathrm{H}$. The cranial nerves. In: Ellis $\mathrm{H}$, editor. Clinical Anatomy. 11th ed. Oxford (UK) s Ltd: Blackwell Publication: 2002. p. 365-66.

3. Hansen $\mathrm{HC}$, Helmke K. Validation of the optic nerve sheath response to changing cerebrospinal fluid pressure: ultrasound findings during intrathecal infusion tests. J Neurosurg. 1997;87 (1):34-40. PMID: 9202262.

4. Merceron S, Geeraerts T. Ocular sonography for the detection of raised intracranial pressure. Expert Rev Ophthalmol. 2008;5 (5):497-500.DOI: 10.1586/17469899.3.5.497.

5. Chan PYN, Mok KL. Transorbitalsonographic evaluation of optic nerve sheath diameter in normal Hong Kong Chinese adults. Hong Kong J Emerg Med. 2008;15(4):197-205.

6. Bratton SL, Chestnut RM, Ghajar J, McConnell Hammond FF, Harris $\mathrm{OA}$, Hartl R, et al. Guidelines for the management of severe traumatic brain injury. VII. Intracranial pressure monitoring technology. J Neurotrauma. 2007;24(1):45-54.PMID: 17511545.

\section{LIMITATIONS}

Study didn't measure ICP directly which would have allowed us to compare and validate how well the ONSD and ICP would have correlated with each other.Study did not include any subjects below 16 years of age.

\section{CONFLICT OF INTEREST}

None

7. Andrews PJ, Citerio G, Longhi L, Polderman K, Sahuquillo J, Vajkoczy P. NICEM consensus on neurological monitoring in acute neurological disease. Intensive Care Med. 2008;34(8):1362-70. PMID: 18398598 .

8. Chesnut RM, Temkin N, Carney N, Dikmen S, Rondina C, Videtta W, et al. A trial of intracranial-pressure monitoring in traumatic brain injury. N EngIJ Med. 2012;367(26):2471-81. PMID: 23234472.

9. Mattei TA. Intracranial pressure monitoring in severe traumatic brain injury: who is still bold enough to keep sinning against the level I evidence? World Neurosurg. 2013;79(5-6):602-4. PMID: 23531728.

10. Hartl R, Stieg PE. Intracranial pressure is still number 1 despite BEST:TRIP study. World Neurosurg. 2013;79(5-6):599-600.PMID: 23528795.

11. Hawthorne C, Piper I. Monitoring of intracranial pressure in patients with traumatic brain injury. Front Neurol. 2014;5:121. PMID: 25076934. 
12. Stocchetti N. Could intracranial pressure in traumatic brain injury be measured or predicted noninvasively? Almost. Intensive Care Medicine. 2007;33:1682-3.PMID: 17668183.

13. Helmke K, Hansen HC. Fundamentals of transorbitalsonographic evaluation of optic nerve sheath expansion under intracranial hypertension II: Patient study. Pediatric Radiology. 1996; 26:706-10. PMID: 8805600.

14. Tasker RC, Matthew DJ, Kendall B. Computed tomography in the assessment of raised intracranial pressure in non-traumatic coma. Neuropediatrics. 1990;21:91-4. PMID: 2359489.

15. Holliday PO 3rd, Kelly DL Jr, Ball M. Normal computed tomograms in acute head injury: correlation of intracranial pressure, ventricular size, and outcome. Neurosurgery. 1982;10:25-8. DOI: 10.1227/00006123-198201000-00005.

16. Rajajee V, Fletcher JJ, Rochlen LR, Jacobs TL. Comparison of accuracy of optic nerve ultrasound for the detection of intracranial hypertension in the setting of acutely fluctuating vs stable intracranial pressure: Post-hoc analysis of data from a prospective, blinded single center study. Crit Care. 2012;16:R79. PMID: 22578001.

17. Blaivas $M$, Theodoro $D$, Sierzenski PR. Elevated intracranial pressure detected by bedside emergency ultrasonography of the optic nerve sheath. AcadEmerg Med. 2003;10:376-81. PMID: 12670853.

18. Major R, Girling S, Boyle A. Ultrasound measurement of optic nerve sheath diameter in patients with a clinical suspicion of raised intracranial pressure. Emergency Medicine Journal: EMJ. 2011; 28:679-81. PMID: 20713366.

19. Moretti R, Pizzi B. Ultrasonography of the optic nerve in neurocritically ill patients. ActaAnaesthesiologicaScandinavica. 2011;55:644-52. PMID: 21463263.

20. Bauerle J, Lochner P, Kaps M, Nedelmann M. Intra- and interobsever reliability of sonographic assessment of the optic nerve sheath diameter in healthy adults. J Neuroimaging. 2012;22(1):42-5. PMID: 21121998.

21. Ballantyne SA, O'Neill G, Hamilton R, Hollman AS. Observer variation in the sonographic measurement of optic nerve sheath diameter in normal adults.European Journal of Ultrasound. 2002;15:145-9. PMID: 12423741.
22. Ballantyne J, Hollman AS, Hamilton R, Bradnam MS, Carachi R, et al. Transorbital optic nerve sheath ultrasonography in normal children. Clinical Radiology. 1999;54:740-2. PMID: 10580764.

23. Maude RR, Hossain MA, Hassan MU, Osbourne S, Sayeed KL, Karim $M R$, et al. Transorbitalsonographic evaluation of normal optic nerve sheath diameter in healthy volunteers in Bangladesh. PLoS One. 2013;8:810-13. PMID: 24312515.

24. Lee JS, Lim DW, Lee SH, Oum BS, Kim HJ, Lee HJ. Normative measurements of Korean orbital structures revealed by computerized tomography. ActaOphthalmol Scand. 2001;79:197- 200. DOI: 10.1034/j.16000420.2001.079002197.x.

25. Bershad EM, Humphreis WE, Suarez JI. Intracranial Hypertension. Semin Neurol. 2008;28(5):690-702. PMID: 19115175.

26. Baral B, Agrawal A, Cincu R. Intracranial pressure monitoring: Concepts in evaluation and measurement. Pak J Med Sci. 2007;23(5): 798-804.

27. Ahmad I, Wahab S, Chana RS, Khan AS, Wahab S. Role of Transcranial Doppler and Pressure Provocation in Evaluation of Cerebral Compliance in Children with Hydrocephalus. HK J Paediatr. 2008;13:110-15.

28. Steiner LA, Andrews PJD. Expand and Monitoring the injured brain: ICP and CBF. Br J Anaesth. 2006; 97(1):26-38.PMID: 16698860.

29. McNamara B, Ray J, Menon D, Boniface S. Raised intracranial pressure and seizures in the neurological intensive care unit. $\mathrm{Br} J$ Anaesth.2003;90(1):39-42.DOI: 10.1093/bja/aeg008.

30. Ailawadhi P, Agrawal D, Sharma BS. Delayed rise in intracranial pressure in patients with head injury.Indian J Neurotrauma. 2010;7(1):37-40. DOI: 10.1016/S0973-0508(10)80009-7.

31. Asghar A, Hashmi M, Hussain A. Optic nerve sheath diameter evaluated by transorbitalsonography in healthy volunteers from Pakistan. Anaesth Pain \& Intensive Care, 2015; 19(3): 282-86.

32. Shrestha GS. Transorbitalsonographic evaluation of optic nerve sheath diameter in healthy Nepalese adults. Neuroanaesthesiol Crit Care. 2016;3:115-118.DOI: 10.4103/2348-0548.182343. 